\section{Depression in physical illness}

Angharad Ruttley MRCPsych,

Specialist Registrar in Psychiatry

Steven Reid MRCPsych PhD,

Consultant in Liaison Psychiatry

Department of Liaison Psychiatry,

St Mary's Hospital, London

Clin Med 2006;6:533-6

The diagnosis of depression in patients with physical illness is challenging. Symptoms of depression occur commonly but it is not always clear when they merit clinical attention. Depressive illness is more prevalent in patients with medical conditions than in the general population and results in substantial disability and healthcare costs. ${ }^{1}$ Despite this, there remains a perception that depression is an 'understandable' reaction to a serious illness. It is, however, usually treatable and, as well as improving mood, treatment may reduce somatic complaints.

\section{Clinical features and diagnosis}

Psychological symptoms associated with physical illness are very common but do not always indicate a depressive illness. Adjustment disorders commonly follow the onset of an acute illness. Symptoms of low mood, anxiety, guilt and hopelessness develop in response to an identifiable stressor but are not persistent. The boundary between adjustment and depressive disorders is not clear-cut but the key determinant should be the severity and duration of symptoms.
Screening questions may be useful in settings where mood is not routinely assessed: ${ }^{2}$

During the last month, have you often been bothered by:

- feeling down, depressed or hopeless?

- having little interest or pleasure in doing things?

Other indicators of a possible mood disorder are:

- failure to adjust to the illness

- poorer physical functioning

- slower recovery than would be expected

- reduced social interaction.

Five or more symptoms of depression that persist over a two-week period are indicative of a depressive illness that warrants specific treatment (Table 1). ${ }^{3}$ Asking about self-harm is essential as chronic physical illness (particularly cancer, HIV and AIDS, renal disease and chronic pain) is associated with an increased risk of suicide.

Symptoms such as insomnia and appetite change may also be due to physical illness, but in assessing depression there is no evidence that taking account of somatic complaints leads to over-diagnosis. In fact, depression comorbid with physical illness is often missed for reasons such as:

- misattribution of symptoms as a normal or realistic response to illness

- negative attitudes to a diagnosis of depression

\section{Key Points}

Up to a third of physically ill patients attending hospital have depressive symptoms

Depression should not be considered an understandable reaction to physical illness

Treatment with antidepressants is safe and effective in physical illness and may improve overall health outcomes

Asking about self-harm is an essential part of the assessment of depression in the physically ill

KEY WORDS: antidepressant, depression, mood disorders, physical illness, suicide
- unwillingness of patients to report symptoms

- unsuitability of the clinical setting for the discussion of emotional problems.

\section{Epidemiology}

Up to a third of physically ill patients attending hospital have depressive symptoms. There is a clear association in community samples between the number of physical symptoms and the number of symptoms of mood disorder. A large population-based study (115,000 subjects) reported the prevalence of major depression in a number of long-term medical conditions (Fig 1). ${ }^{4}$ In contrast to previous studies, the prevalence of depression was higher in younger people.

\section{Pathways to depression}

Depression may occur as a psychological reaction to physical illness, be precipitated by the exacerbation of an illness or the realisation of its serious or disabling nature. Uncertainty about the future, feelings of loss of control and a sense of failure are common responses to illness but do not inevitably lead to depression. Risk factors for the development of a mood disorder include a prior history of depression, low social support, substance misuse, and additional stressful life events such as marital separation or loss of job. Depression can also occur as a specific consequence of physical illness

Table 1. Criteria for diagnosis of depression.

- Persistent sadness or low mood*

- Loss of interests or pleasure*

- Fatigue or low energy*

- Disturbed sleep

- Poor concentration or indecisiveness

- Low self-confidence

- Poor or increased appetite

- Suicidal thoughts or acts

- Agitation or slowing of movements

- Guilt or self-blame

* One of these symptoms must be present. 


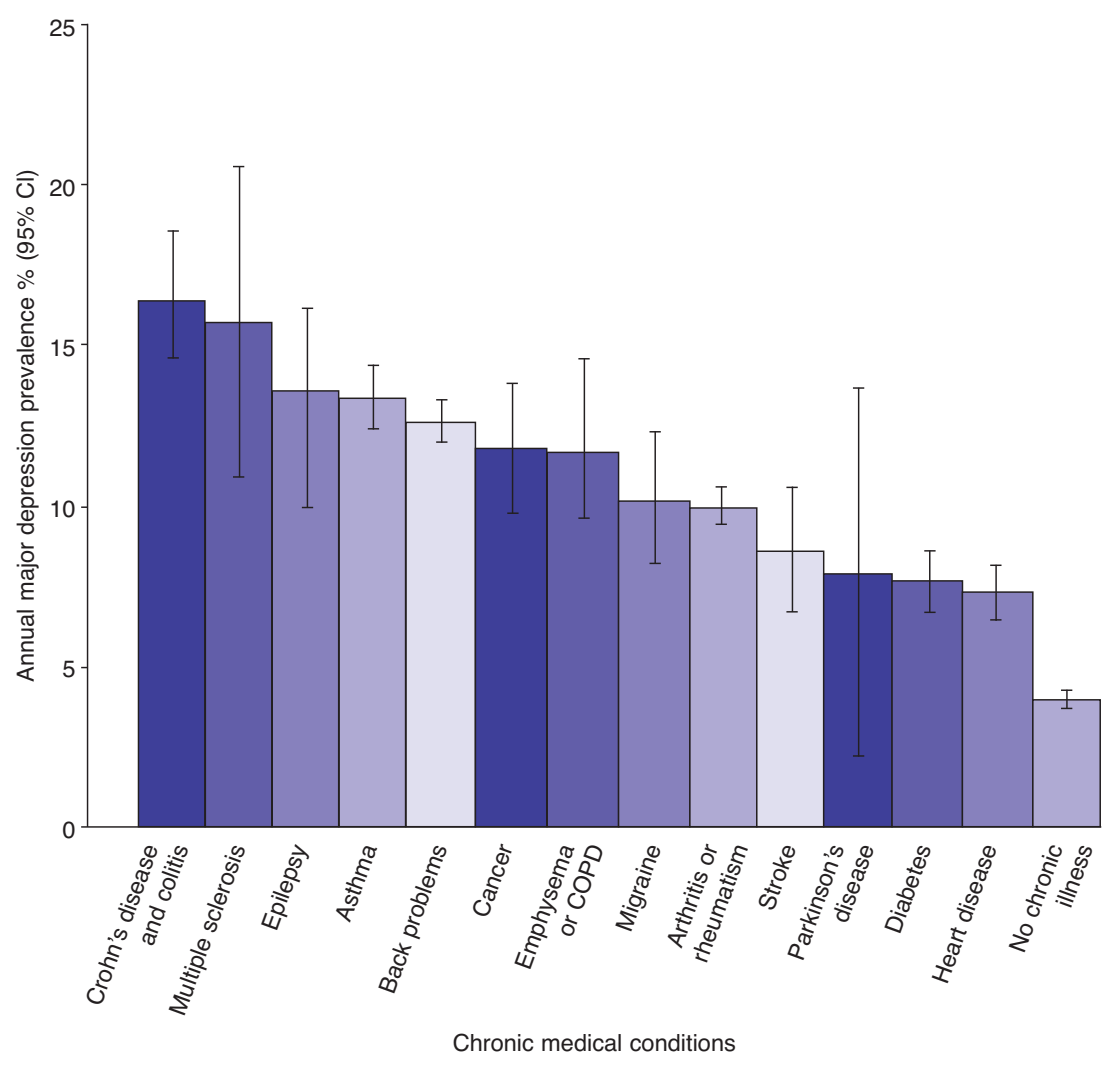

Fig 1. Prevalence of major depression in self-reported long-term medical conditions. Reproduced with kind permission of the Canadian Journal of Psychiatry. ${ }^{4}$ $\mathrm{Cl}=$ confidence interval; $\mathrm{COPD}=$ chronic obstructive pulmonary disease.

or as an adverse effect of drug treatment (Table 2). It may sometimes be the sole presenting symptom of an underlying disease (eg carcinoma of the pancreas); this should be considered particularly in people presenting with depression for the first time in later life.

\section{Management of depression in the physically ill}

For patients with minor depressive symptoms and adjustment disorders, explanation, support and reassurance can reduce fear and uncertainty and anti- depressants are not usually required. ${ }^{3}$ Patients with more enduring or severe symptoms will need specific treatment, usually drug treatment in the first instance.

\section{Antidepressants}

The use of antidepressants in patients with physical illness is often complicated by concerns about adverse effects and drug interactions. The range of available drugs can also be confusing. There are four main classes of antidepressant:

- tricyclic antidepressants (TCAs) (eg amitriptyline)

- selective serotonin reuptake inhibitors (SSRIs) (eg fluoxetine)

- monoamine oxidase inhibitors (rarely used today)

- others (eg venlafaxine).

There have been only a limited number of trials of antidepressants in patients who are also physically unwell but the available evidence supports their use. A systematic review of 18 controlled studies concluded that treatment with antidepressants led to significant improvements in depression associated with a range of physical illnesses compared with placebo or no treatment. ${ }^{5}$ Antidepressant treatment was reasonably acceptable to patients, with SSRIs and TCAs showing equivalent tolerability. There is also substantial evidence for the safety of SSRIs in ischaemic heart disease and recent myocardial infarction (MI). In a large

Table 2. Physical illnesses and drugs commonly associated with depression.

\begin{tabular}{|c|c|c|}
\hline Intracranial & Extracranial & Drugs \\
\hline $\begin{array}{l}\text { - } \text { Tumours } \\
\text { - Hurkinson's disease } \\
\text { - Cerebrovascular disease } \\
\text { - Encephalopathies (eg BSE) } \\
\text { - Head injury } \\
\text { - Multiple sclerosis }\end{array}$ & $\begin{array}{l}\text { - } \quad \text { Malignancy } \\
\text { - Indocrine disorders } \\
\text { infections (eg hepatitis B, } \\
\text { inononucleosis) }\end{array}$ & $\begin{array}{l}\text { - } \text { Antihypertensives (reserpine, clonidine, } \\
\text { - } \text { Anti-arrhythmics (digoxin, procainamide) } \\
\text { - Antiparkinsonian (L-dopa, amantadine) } \\
\text { - } \text { Cytotoxic agents (interferons, vincristine) } \\
\text { - } \mathrm{H}_{2} \text {-blockers (cimetidine) } \\
\text { - } \text { Hormonal agents (corticosteroids, anabolic } \\
\text { - } \text { steroids, oral contraceptives) } \\
\text { - } \text { Anticonvulsants (barbiturates, } \\
\text { Antiretroviral agents (nevirapine, efavirenz) }\end{array}$ \\
\hline
\end{tabular}

BSE = bovine spongiform encephalopthy 
randomised controlled trial (369 subjects) in patients developing depression within 30 days of an MI, sertraline was safe and effective and there was a trend towards fewer subsequent cardiac events in those treated with the antidepressant than with placebo. ${ }^{6}$ The choice of antidepressant in clinical practice depends on assessment of the individual patient (Table 3). ${ }^{7}$ SSRIs are commonly used in preference to TCAs due to their favourable side-effect profile and greater safety in overdose.

Patient education is essential, particularly about potential adverse effects and that benefits may take 2-4 weeks to become apparent. Antidepressants are often prescribed at inadequate doses for inadequate periods of time. Treatment needs to be continued for at least four months at full dose to consolidate remission and prevent relapse.

Patients with physical illness are likely to be taking additional prescription medicines so an awareness of the potential for drug interactions both with prescribed and over-the-counter medicines is important. Worthy of especial attention is St John's wort, a herbal preparation that has been shown to be of benefit in mild to moderate depression. ${ }^{8}$ However, it is inadvisable to recommend this drug as there is uncertainty about the appropriate dose, and available preparations vary markedly. Most importantly, it is a potent inducer of the hepatic cytochrome system and may interact with prescribed drugs causing serious adverse effects.

\section{Psychological treatments}

Psychological treatments may be particularly desirable in situations where relative contraindications to antidepressants exist either because of physical illness or its treatment. Cognitive-behavioural therapy, interpersonal therapy and problem solving can all be effective for treating depression although - as with drug treatments - there has been comparatively little study of their effectiveness in the general hospital setting. These 'talking treatments' serve to support or improve coping strategies, an important aspect of treatment in physically ill patients. They are time-consuming but in the longer term may reduce the likelihood of relapse.

\section{Specialist referral}

Most physically ill patients with depressive symptoms are managed successfully by the medical team but a minority will warrant referral to a mental health specialist because of the complexity of the presentation or when there are concerns about risk. Referral to a psychiatrist or psychologist may be difficult if the patient is unprepared. An explanation of the purpose of the referral is important and the patient may need reassurance that they are not 'mad' or 'hopeless'. Situations when referral to a psychiatrist is indicated are:

- severe depression (eight or more symptoms)

- lack of response to treatment

- active suicidal thoughts or plans

- psychotic symptoms (hallucinations, delusions)

- severe self-neglect

- patient's request.

Table 3. Use of antidepressants in selected medical disorders.

\begin{tabular}{|c|c|c|c|}
\hline Medical disorder & Tricyclic antidepressants & $\begin{array}{l}\text { Selective serotonin } \\
\text { reuptake inhibitors }\end{array}$ & Newer antidepressants* \\
\hline Cardiovascular disease & $\begin{array}{l}\text { Should be avoided } \\
\text { Increased risk of arrhythmias } \\
\text { due to prolongation of QT and } \\
\text { QRS intervals } \\
\text { Reduce myocardial contractility } \\
\text { Risk of postural hypotension }\end{array}$ & $\begin{array}{l}\text { Generally considered safe } \\
\text { Now advised that treatment } \\
\text { should not be withheld post-MI } \\
\text { (sertraline has no licensed } \\
\text { restrictions) } \\
\text { Mild anticoagulant effect }\end{array}$ & $\begin{array}{l}\text { MHRA recommends avoiding } \\
\text { venlafaxine in cardiovascular disease }\end{array}$ \\
\hline Stroke & $\begin{array}{l}\text { Nortriptyline has the most } \\
\text { supportive research evidence }\end{array}$ & $\begin{array}{l}\text { Considered safe, but citalopram } \\
\text { advised if patient on warfarin }\end{array}$ & Very little data \\
\hline Liver disease & $\begin{array}{l}\text { Likelihood of increased } \\
\text { sensitivity to adverse effects, } \\
\text { particularly sedation, so should } \\
\text { be used with caution } \\
\text { Lofepramine is contraindicated }\end{array}$ & $\begin{array}{l}\text { Generally considered safe to use } \\
\text { in renal disease with caution } \\
\text { Avoid fluoxetine due to extensive } \\
\text { hepatic metabolism and long } \\
\text { half-life }\end{array}$ & $\begin{array}{l}\text { Dose reduction recommended for all } \\
\text { in renal impairment }\end{array}$ \\
\hline Renal disease & $\begin{array}{l}\text { Generally considered safe to } \\
\text { use with monitoring for urinary } \\
\text { retention, confusion sedation } \\
\text { and postural hypotension }\end{array}$ & $\begin{array}{l}\text { Generally considered safe to use } \\
\text { with caution }\end{array}$ & $\begin{array}{l}\text { Use with caution } \\
\text { MHRA recommends avoiding } \\
\text { venlafaxine in patients with } \\
\text { electrolyte disturbance }\end{array}$ \\
\hline Epilepsy & $\begin{array}{l}\text { Should be avoided as TCAs } \\
\text { reduce seizure threshold }\end{array}$ & $\begin{array}{l}\text { Use with caution although } \\
\text { SSRIs have low proconvulsive } \\
\text { effect }\end{array}$ & $\begin{array}{l}\text { Moclobemide not known to be } \\
\text { proconvulsive } \\
\text { Little data available on others }\end{array}$ \\
\hline
\end{tabular}

